\title{
TRENDS AND CONSTRAINTS FOR FLUID POWER IN MOBILE MACHINERY
}

\author{
Roberto PAOLUZZI* \\ Institute for Agricultural and Earthmoving Machinery - Italian National Research Council IMAMOTER - \\ C.N.R. Via Canal Bianco, 2844100 Ferrara - Italy \\ E-mail r.paoluzzi@imamoter.cnr.it
}

\begin{abstract}
The development of fluid power systems for use in agricultural and construction machinery faced in the last years a substantial contribution due to the increasing role played by electronics. The scenario of the next years in agricultural and construction will be very much influenced by legislation constraints in terms of environmental compatibility, noise emission, energy usage and recyclability. The new set of requirements in terms of safety level for machines, described in documents like ISO 15998:2008 will change the boundary conditions for machine design, requiring a deep investigation at system level, which will force a change in the design perspective for fluid power components. The new possibilities given by an extensive use of embedded electronics, advanced architectures and system level design of machines will be investigated and described trying to highlight threats and opportunities for next generation of products.
\end{abstract}

\section{KEY WORDS}

Hydraulic system, Mobile machinery, Electronic system, energy saving, sustainability

\section{INTRODUCTION}

The deep changes in hydraulic circuit layout due to the extensive use of electronics and distributed control is an unquestionable feature which characterized the evolution of high-end products over the last decade. However, the potential offered by the novel approach is not fully exploited since, with some remarkable exceptions, it affected mainly hydraulic components, seen as individual parts, performing local functions. The availability of a large amount of information on system variables, and the ability of control systems to react to abrupt changes in the operating environment, is one of the key features of fluid power systems coupled with electronic control. It can overcome the major limitations, in terms adaptation, shown by traditional hydro-mechanical approach.

On one hand, the mobile machinery industrial sector is one of the trailers in view of the reduced cost and improved flexibility of electronics, but on the other hand, the target of the efforts is strongly influenced by legislation constraints in machinery use. These constraints, after a long period of independent evolution, are now converging towards a global approach, where America, European and Asian markets tend to share a common objective. The paper tries to highlight these mid- or long-term objectives focusing on the way they can affect the development of fluid power systems for mobile use.

\section{MAJOR CONSTRAINTS NOISE EMITTED BY OUTDOOR EQUIPMENT}

European Directive 2000/14/EC [1], amended by the Directive 2005/88/EC of the European Parliament and of the Council of 14 December 2005, corrected by Corrigendum to Directive 2005/88/EC (OJEU L 165, 
17.6.2006, p. 35), concerning the noise emitted by equipment used outdoor, enforced strict limits on noise emission by mobile machinery, according to a long-term reduction strategy. Several machines (mainly earthmoving) were strongly affected by limits imposed and needed specific measures to be undertaken in order to improve their noise emission level. Apart from other side effects, which will be dealt with later, the first result of reduction in noise emissions from the main sources (engine and cooling fan) is the increased importance of hydraulic components as a noise source [2].

Research on noise reduction in fluid power components has always been a very active area, but in recent years a renewed attention revitalized the area, thanks to the pressure that machine manufacturers are exerting on hydraulic suppliers in order to get quieter components. Figure 1 shows the situation on noise emission values from hydraulic excavators as function of net engine power, prior to directive 2000/14/EC enforcement

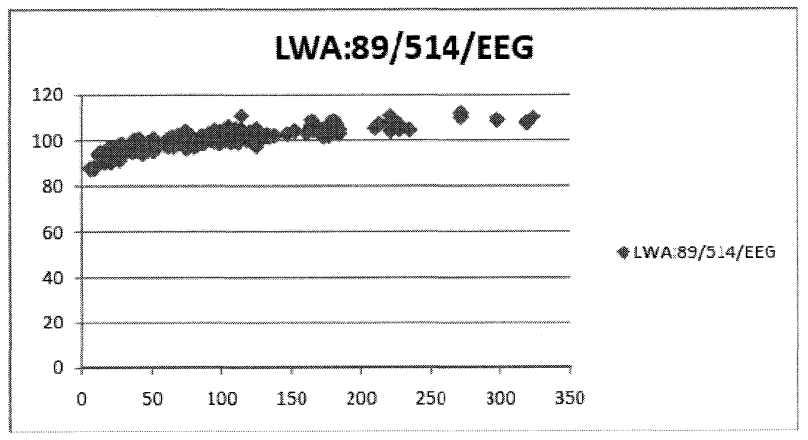

Figure 1 Emissions from off-road diesel engines in Europe

It is worth noting that emitted noise values are significantly above $100 \mathrm{~dB}(\mathrm{~A})$ for a large part of installed power range.

Figure 2 shows the guaranteed noise levels admissible for excavators according to the requirements of the Directive 2000/14/EC.

A first comment is that the limits can be challenging for several machines, and according to several analysis of statistical data, in an excavator for example, the engine noise, fan noise and hydraulic noise can all be at a similar level, and in that case all need to be reduced together [13]. It is worth noting that at the time of switching from stage I levels (third column of figure 2) to stage II (last column), a remarkable $20 \%$ of the machines could not meet the requirement [13].

\section{EMISSIONS FROM I.C. ENGINES}

The topic of limitations to emissions of $\mathrm{CO}_{2}$ and $\mathrm{No}_{\mathrm{x}}$ from internal combustion engines used off-road, Directive $97 / 68 / \mathrm{EC}$, amended by $2004 / 26 / \mathrm{EC}$ and
$2006 / 105 / \mathrm{EC}$ is another of the environmental and legislation constraints able to change the overall scenario

\begin{tabular}{|c|c|c|c|}
\hline \multirow{2}{*}{ 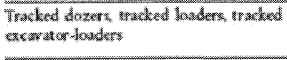 } & $P \leq 35$ & 106 & 1036 \\
\hline & $P>55$ & $8 z+11 \lg P$ & $84+11 \mathrm{lg} P(0)$ \\
\hline \multirow{2}{*}{ 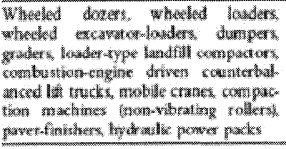 } & $P \div 55$ & 104 & $101(9)$ \\
\hline & $p>35$ & $85+11 \mathrm{lg} P$ & $82 * 11 \mathrm{gP} P(9)$ \\
\hline \multirow{2}{*}{ 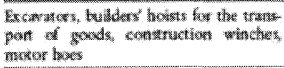 } & $P \leq 15$ & 96 & 93 \\
\hline & $p>15$ & $B 3+11 \lg P$ & $80+111 \mathrm{lg}$ \\
\hline
\end{tabular}

Figure 2 permissible noise levels according to EC directive (dBA)

of boundary conditions that fluid power systems must comply with. If apparently this actions does not directly affect fluid power systems, when combined to noise emission limits it had, and will have, tremendous impact on design.

Figure 3 shows the evolution of limit emissions from I.C.engines according to European legislation, but the scenario does not change much if we refer to EPA in USA (figure 4) or Japan (Figure 5)

Mobile machinery are significantly impacted in the sense that up to $100 \%$ of the available power is transferred to implements or locomotion devices though hydraulic subsystems, and the coupling between demand and available power determines the engine working point and therefore its emissions.

The effect on machine constraints can be summarized as follows:

- Engine displacement becomes generally larger;

- $\quad$ Rated engine speed is generally reduced;

- Cooling system design is more stringent (also due to noise limitation)

- Electronic injection control is generalized

\begin{tabular}{|c|c|c|c|c|c|}
\hline \multirow[t]{2}{*}{ Cat. } & Not Power & \multirow{2}{*}{ Datot } & co & $\mathrm{NO}, \mathrm{HC}$ & PM \\
\hline & $k W$ & & \multicolumn{3}{|c|}{$g k W n$} \\
\hline A & $130 \leq P \leq 560$ & 2006.01 & 3.5 & 4.0 & 0.2 \\
\hline 1 & $75 \leq P<130$ & 2007.01 & 500 & 4.0 & 0.3 \\
\hline$j$ & $37 \leq P<75$ & 2006.01 & 50 & $4 . \%$ & 0.4 \\
\hline k & $19 \leq P=37$ & 2007,01 & 5.5 & 7.5 & 0.6 \\
\hline
\end{tabular}

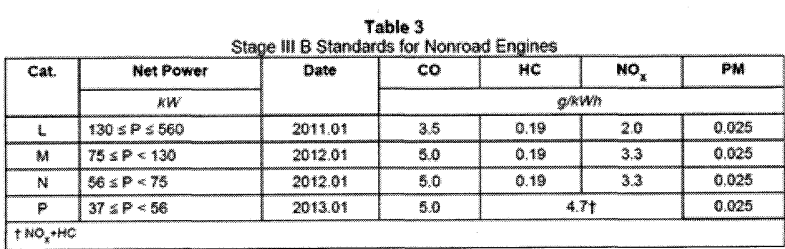

Figure 3 Emissions from off-road diesel engines in Europe 


\begin{tabular}{|c|c|c|c|c|c|c|}
\hline Engine Power & Year & co & NMHC & NGHC +NO & NO $_{x}$ & PM \\
\hline $\begin{array}{l}k W<8 \\
(n p<11)\end{array}$ & 2000 & $8.0(6.0)$ & . & $7.5\{5.6\}$ &. & $0.4^{a}\{0.3\}$ \\
\hline $\begin{array}{l}8 \leq \mathrm{kW}<19 \\
(11 \leq \mathrm{hp}<25)\end{array}$ & 2000 & $6.6(4.9)$ & - & $7.5(5.6)$ & $=$ & $0.4(0,3)$ \\
\hline \multirow{2}{*}{$\begin{array}{l}19 \leq \mathrm{kW}<37 \\
(25 \leq \mathrm{hp}<50)\end{array}$} & 20000 & $5.5(4.1)$ & $=$ & $7.5(5.6)$ & 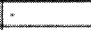 & $0.3(022)$ \\
\hline & 2013 & $5.5(4.1)$ & - & $4.7(3.5)$ & . & $\begin{array}{l}0.03 \\
0.022)\end{array}$ \\
\hline \multirow{2}{*}{$\begin{array}{l}37 \leqslant k W<66 \\
(50 \leq h p<75)\end{array}$} & 2008 & $50(37)$ & - & $47(35)$ & . & $0.3^{\mathrm{t}}\{0.22)$ \\
\hline & 2013 & $5.0(3.7)$ & $=$ & $4.7(3.5)$ & $=$ & $\begin{array}{l}0.03 \\
0.022\}\end{array}$ \\
\hline $\begin{array}{l}56=k w=130 \\
(75 \leq h p<175)\end{array}$ & $2012.2014^{\circ}$ & $5.0(3.7)$ & $0.19(0.14\}$ & . & $0.4010 .30\}$ & $\begin{array}{l}0.02 \\
(0.015)\end{array}$ \\
\hline $\begin{array}{l}130 \leq k W \leq 600 \\
(775 \leq 50 \leq 750\}\end{array}$ & $2011: 2014^{d}$ & $3.5(2.6)$ & $0.19(0.14)$ & & $0,40\{0.30\}$ & $\begin{array}{l}0.02 \\
0.015\}\end{array}$ \\
\hline
\end{tabular}

Figure 4 Emissions from off-road diesel engines in USA

\begin{tabular}{|c|c|c|c|c|c|c|c|}
\hline \multirow{2}{*}{$\begin{array}{c}\text { Power }(\mathbf{P}) \\
k W\end{array}$} & co & HC & NOX & PM & \multirow{2}{*}{$\frac{\text { Smoke }}{\%}$} & \multicolumn{2}{|c|}{ Date } \\
\hline & \multicolumn{4}{|c|}{$g / k W h$} & & New Models & All Modelst \\
\hline $19 \leq P<37$ & 5.0 & 10 & 6.0 & 0.4 & 40 & 2007.10 & 2008.09 \\
\hline $37 \leqslant P<56$ & 5.0 & 0.7 & 4.8 & 0.3 & 35 & 2008.10 & 2009.09 \\
\hline $56 \leq P<75$ & 5.0 & 0.7 & 4.0 & 0.25 & 30 & 2000.10 & 2010.09 \\
\hline $75 \leq P<130$ & 5.0 & 0.4 & 3.6 & 0.2 & 25 & 2007.10 & 2008.09 \\
\hline $130 \leq P<560$ & 3.5 & 0.4 & 36 & 0.17 & 25 & 2006.10 & 2008.09 \\
\hline
\end{tabular}

Figure 5 Emissions from off-road diesel engines in Japan

The effects on fluid power systems, to be considered additional to the noise effect already highlighted, are various:

- Increase of operating temperatures

- Variation in the torque-speed characteristic of i.c. engine

- Need to control the i.c. operating point shift due to load characteristic of fluid power subsystem

- Increased attention to overall efficiency and specific fuel consumption in actual operation

- Need for transparent interface between engine and fluid power systems electronic control

The above mentioned aspects more or less can be tackled with the system-wide approach to fluid power systems design, boosting the activity towards the development and adaptation of advanced system architectures also for small and medium size machinery $[6,7]$, with implications that will be discussed in the next paragraphs. A different effect is the increase of operating temperatures, which will rise beyond the traditionally considered threshold of $90^{\circ}$ Celsius, to reach in most cases stable values above $100^{\circ}$. Most manufacturers already seek component and system qualification above those values, but design methods generally do not take into account the effects of this increase, both in terms of fluid performance and material compatibility. This temperature trends will influence fluid characteristics, material and component endurance and gathering of proper data on efficiency and service life of components.

\section{ELECTRONICS AND SENSORS}

The introduction of electronics in fluid power systems is not a new trend. It started in ' 90 s and nowadays can be considered a settled achievement, widely accepted by the market.

However only in recent products the potential of this technology starts to be fully exploited. Notable examples in this field are the dedicated electronic control strategies for fluid power subsystems applied by more or less all the major earth moving machinery manufacturers and/or dedicated ranges of application optimized hydraulic components like the Electronic Flow Match (EFM) or Bodas by Bosch-Rexroth.

Also research is very active in this field and many new applications or strategies try to use electronics to find a best match between hydraulic subsystem and application $[7,8]$. In view of an exploitation of the perspectives in this field, some aspects are worth mentioning:

1. The number, location, precision and reliability of sensors will increase, as well as their degree of integration inside components;

2. Electro-hydraulic components will perform more and more complex actions, rather than receiving and applying an external command, being part of a common, distributed control system with increased need for data transfer throughput and reliable protocol;

3. Being a large amount of controls relying on electronic boards and programmable devices, safety issues require special treatment

The first two aspects have been broadly investigated by many authors and do not need special focus here; however the third is more impacting in the field of mobile off-road equipment $[9,10,11]$.

The focus of new standards is on functional safety (much broader than component integrity), which will force functional analysis to become a common task, switching the focus from le component level to the system level, in evaluating a fluid power system. As an example, Figure 6 shows the flow chart for functional safety implied by the newly published ISO 15998 standard.

Most applications will need the certification of their Safety Integrity Level (SIL), according to EN 954 and EN 61508, and the impact of this requirement is much more extended than a trivial need for third party certification. The full approach to design of components and systems for mobile hydraulics must change, and concepts like reliability assessment, probabilistic design, risk management must become common practice for the fluid power component design.

A design can be completely scrambled by the switch from pure performance achievement to safe function certification, expecially when safety critical applications are concerned, like X-by-wire systems, lifting systems or travel control systems are concerned.

The evaluation of Safety Integrity Level (Figure 7) is a complex task, involving multidisciplinary approach, and which is best performed at early design stages of components and control boards. The close link to 
application demand of this activity will boost the already generalized tendency to specialize fluid power components towards an integrated subsystem specifically tailored on application needs.

\section{SUSTAINABILITY}

The ever increasing attention to environmental and energy issues is having a great impact on standardization activity in the field of off-road machinery.

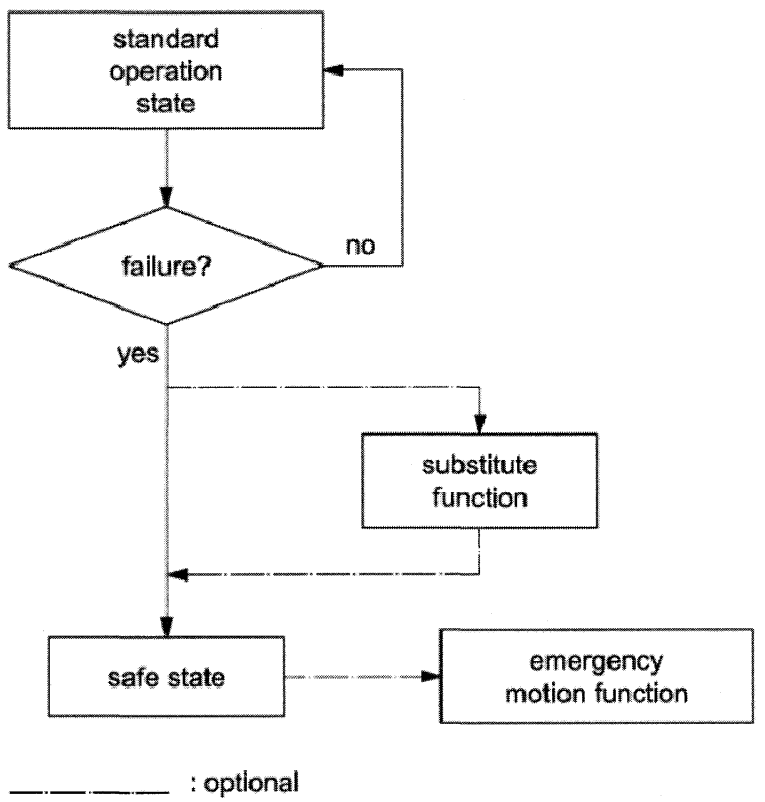

Figure 6 functional safety evaluation chart

ISO/FDIS 16714 is close to final publication, and will introduce a criterion for recyclability assessment of material used in earthmoving machinery. The final target is an ambitious amount of $95 \%$ recyclability in mass, with a significant part of the standard dealing with recyclability of fluid power components. Table 1gives a snapshot of the breakdown of machine mass fractions which are subject to different (pre)treatment.

Table 1 Mass definition for recyclability matrix (adapted from ISO/FDIS 16714)

\begin{tabular}{|c|l|}
\hline Symbol & \multicolumn{1}{|c|}{ Description } \\
\hline$m_{\mathrm{P}}$ & $\begin{array}{l}\text { mass of materials taken into account at } \\
\text { the pre-treatment step }\end{array}$ \\
\hline$m_{\mathrm{D}}$ & $\begin{array}{l}\text { mass of materials taken into account at } \\
\text { the dismantling step }\end{array}$ \\
\hline$m_{\mathrm{M}}$ & $\begin{array}{l}\text { mass of metals taken into account at the } \\
\text { metal separation step }\end{array}$ \\
\hline
\end{tabular}

\begin{tabular}{|c|l|}
\hline$m_{\mathrm{Tr}}$ & $\begin{array}{l}\text { mass of materials taken into account at } \\
\text { the non-metallic residue treatment step } \\
\text { and which can be considered as } \\
\text { recyclable }\end{array}$ \\
\hline$m_{\mathrm{Te}}$ & $\begin{array}{l}\text { mass of materials taken into account at } \\
\text { the non-metallic residue treatment step } \\
\text { and which can be considered for energy } \\
\text { recovery }\end{array}$ \\
\hline $\mathbf{S M}$ & shipping mass (ISO 6016) \\
\hline
\end{tabular}

Fluid power components and hydraulic fluids will play a non marginal role, and their ability to be easily dismantled, recycled and possibly handled with a minimum energy usage will ease the application in offroad machinery. All of them are listed as components to be considered for pre-treatment, with the relevant

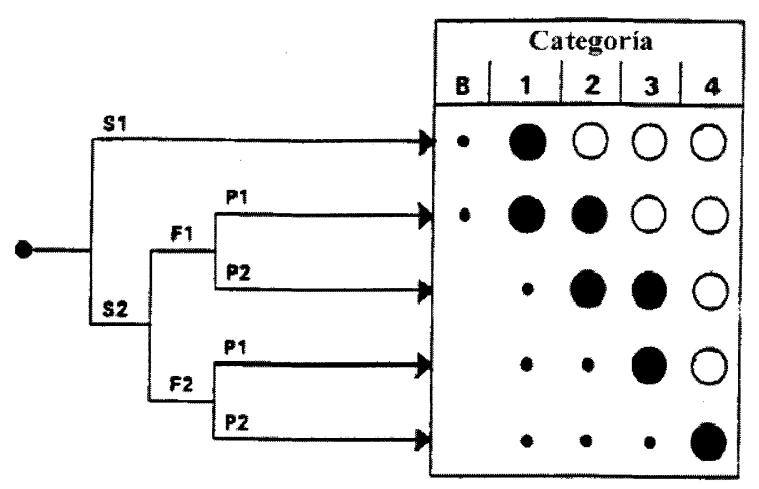

Figure 7 evaluation of Safety Integrity Level

exception of flexible hoses, filter cartridges and accumulators, which are to be accounted as non-metallic residue for which the availability of a proven technology for separation, recycling or energy recovery must be shown. The machine recyclability rate is defined in the standard as

$$
R_{c y c}=\frac{m_{P}+m_{D}+m_{M}+m_{T r}}{S M} \times 100
$$

And the recoverability rate (which includes energy recovery) is given as

$$
R_{C O V}=\frac{m_{P}+m_{D}+m_{M}+m_{T r}+m_{T e}}{S M} \times 100
$$

The details are not relevant at this stage, but the content of the standard clearly shows a general trend in material life cycle assessment which is further amplified by recent attention in terms of sustainability of the entire life cycle of the machine. 
A mobile machine, as far as sustainability is concerned, is an "energy consuming product" in the sense of the existing legislation. It is a shared opinion that for offroad operating machinery more than $80 \%$ of sustainability is in the efficiency of energy use by the machine (i.e. fuel specific consumption). This consideration is only apparently trivial. It means that most of the efforts in developing new products, systems and controls must be in the direction to induce energy savings in the machines during actual operation.

\section{ENERGY USE}

The concept of energy use automatically calls for efficiency. The concept of efficiency, however, apart from its apparent simplicity, as a ratio between energy or power output and input of a system or component can be tricky. Evaluation of efficiency depends on placement of the boundary of the domain where efficiency is computed, and on choice of the duty cycle of the component. In case of steady state operation, does not matter if power ratio or energy ratio is evaluated, as in this case instant efficiency, work cycle efficiency and lifetime efficiency are equal. Unfortunately this situation is far from being a real life case in off-road machinery. CVT (power-split) transmissions, introduced in the early '50s have been considered a little more than a curiosity for a long time, just because their steady state efficiency was significantly lower than mechanical or powershift transmissions. Only in recent years their intrinsic capability to adapt to different working conditions has been recognized as a key factor to get better efficiency in complex working cycles, with high and unpredictable load changes.

A similar approach applies if we look at the concept of efficient energy use of earth moving or agricultural machinery. Prime mover, hydraulic pumps and motors, transmissions, locomotion gears and implements have individual efficiency which depends on the operating point, with variations in the range of operation as high as $60-70 \%$. Efficiency maps of the different parts of the energy path from prime mover to implements do not match to each other, and therefore the quest for optimal efficiency is a continuous struggle to find the best compromise among different needs.

This aspect is evident not only in many research papers and new products from leading manufacturers, but also in the international standardization activity. ISO/TC 127, Earthmoving machinery, recently started a high priority new work item on test methods for efficient energy use, with the objective to make a reference procedure available to rate machine energy consumption in working conditions as representative of actual usage as practicable. Japan government have been promoting to establish the specific and effective "Measures to Prevent Global Warming". As one of measures in the area of

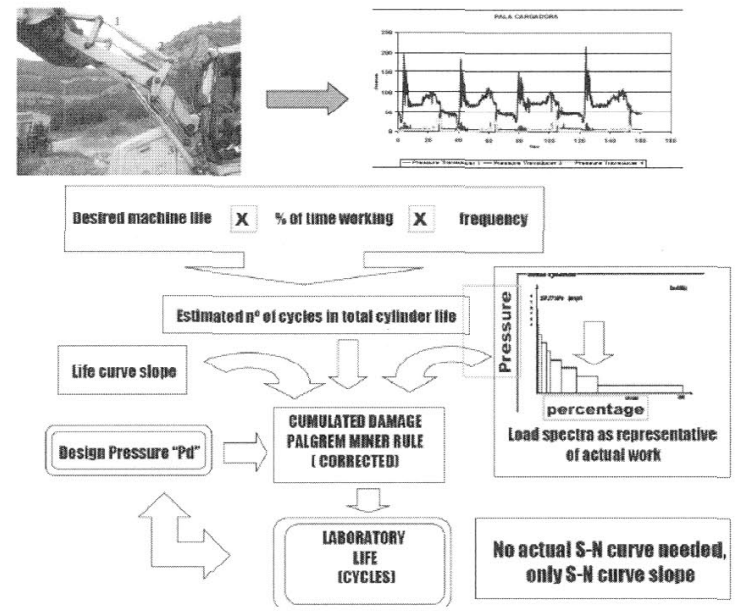

Figure 8 From field data to component qualification - PROHIPP design approach (Courtesy of Pedro Roquet SA - Spain)

construction method, it would be required to improve fuel consumption of construction machinery and to be able to select more "fuel-efficient" machines. Three test procedures about hydraulic excavator, tractor-dozer and wheel loader were released as JCMA standards(JCMAS) in May 2004. Afterwards, Revision of the standard has been advanced to improve accuracy, repeatability, reproducibility, and variance. This work is being used as a starting point for ISO activity.

Fluid power industry must take the opportunity offered by this expected boost in efficiency, with a deeper consideration of actual duty cycles of components in different applications and an improved control of the two main interfaces affecting efficiency: pump(s)-engine and soil-implement(s)

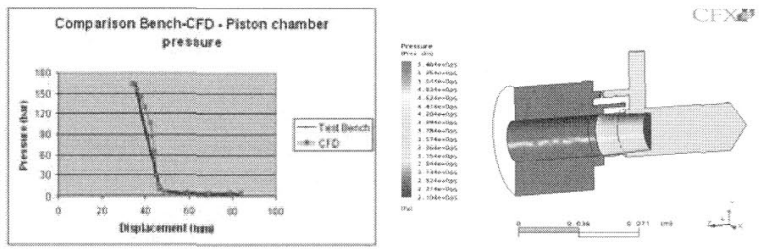

Figure 9 Example of advanced use of Computational Fluid Dynamics for cylinder cushioning design (IMAMOTER - PROHIPP project [12])

Advanced simulation tools are also a great opportunity, with their increased ability to perform multi-physics simulations and to include control systems analysis and synthesis. Application of virtual reality (VR) tools to machine design is already a common practice for many machine manufacturers, in view of ergonomics, visibility and maintenance optimization. However advanced simulation tools allow a better insight also to fluid power components, in order to get the information needed to improve design methods and system reliability. The EU funded project PROHIPP is such an example. It is aimed 
at developing a novel, category based, probabilistic design applied to hydraulic cylinders, making an extensive use of advanced simulation tools for approach validation. Figure 8 is an example of the categories definition proposed, depicting a scenario which is consistent with a reliability evaluation approach in line with the already discussed SIL level for electronic subsystem.

An example of the level of insight made available by advanced simulation tools is the evaluation of cushioning device on hydraulic cylinders. The non-linear simulation and the CFD investigation gave full insight into the behavior, explaining and highlighting specific features such as oscillatory behavior and/or sealing damage due to the presence of unbalanced radial forces in cushioning stroke. Figure 9 shows the pressure field at a specific moment in time of the cushioning, and the comparison with the corresponding experimental results in one of the three specific designs investigated. The data reproduction is extremely good, validating the confidence on the set of parameters which can be derived by a numerical simulation and which cannot be measured in a physical experiment, such as discharge coefficients, turbulence parameters and surface pressure distribution. A full description of the findings of the project is beyond the scope of this paper, but they proof that the extensive, concurrent use, of advanced simulation tools, properly coordinated with experimental activity will make the probabilistic approach to design a feasible task for fluid power components with a significant improvement in machine reliability and efficiency, thanks to the reduced impact of oversized (or ill-sized) design usually implied by a traditional approach based on safety factors.

\section{CONCLUSIONS}

Future trends in fluid power will be highly constrained by the increasing demand by legislation and associated social concern about mobile machinery impact on environment and safety. However this situation should not be considered as a threat, but rather as an opportunity to improve performance and to drive the introductions of new technologies, materials and design approach. New approaches will be required in view of performance assessment and design practice and some of them could take advantage of technology transfer from more other sectors, such as automotive and aerospace. Nevertheless a significant possibility exist to develop original approaches in the field of system-wide approach to design and manufacture, application of integrated computer-assisted techniques and improvement of manmachine-environment interfaces. Building blocks of new achievements are already being developed and in the future, possibly, the overall appearance of machines will not change much, but their internal architecture will undergo a substantial change.

\section{ACKNOLEDGEMENTS}

The author thanks warmly all the partners of the PROHIPP project (www.prohipp.com) for the invaluable amount of information gathered during the four years of the project. PROHIPP is an integrated research project partially funded by the European Commission within the VI Framework Program of the European Union [12]

\section{REFERENCE}

1. Directive 2000/14/EC Of The European Parliament And Of The Council of 8 May 2000 on the approximation of the laws of the Member States relating to the noise emission in the environment by equipment for use outdoors, Official Journal of the European Communities, L 162/1, 3.7.2000.

2. Carletti, E., Casazza, C., Pedrielli, F., "Psychoacoustic characterisation of the noise at the operator position of a compact loader during real working conditions", Proc.s of $19^{\text {th }}$ International Congress on Acoustics ICA2007, Madrid, Spain (27 Sept. 2007), pp. 1-6, ISBN 84-87985-12-2.

3. Carletti, E., "Outdoor Equipment: current situation on noise emissions and strategies for control", Noise/News International magazine, Vol.14, Nr.4, pp.152-154, December 2006

4. White, K. G., Green, B. and Brown, P. F.: Fluid Power Control, WWW Press, U.S.A (2001)

5. Koizumi J. and Yabu J. : New Challenges on Mechatronic Fluid Power, Proc. 55th JHPS Int. Symp. on Fluid Power Osaka '2000, 55/60 (2000)

6. Latour, C., Electrohydraulic flow Matching (EFM), the next generation of load sensing controls, Procs of Mobile 2006 Congress, Bosch-Rexroth AG

7. Marani, P., Ansaloni, G., Paoluzzi, R., Load Sensing With Active Regeneration System, Proc.s of the $7^{\text {th }}$ IJFPS, in publication

8. Andruch, J., Lumkes, J., A Hydraulic system Topography with Integrated Energy Recovery and Reconfigurable Flow Paths Using High Speed Valves, Procs of 2008 NCFP, Las Vegas.

9. M. Hauke, M. Schaefer. Sicherheitsnorm mit neuem Konzept, o+p, 3/2006

10. J. Barg. Sicherheit in der Elektronik Arbeitshydraulik von Telehandlern, o+p, 3/2005

11. Ruggeri, M., Il futuro dell'integrazione elettronica tra norme e tecnologie, Congresso Trasmissioni di Potenza, Assago (MI), Italy, 2007

12. PROHIPP - New Design And Manufacturing Processes For High Pressure Fluid Power Products, EU Integrated Research Project, NMP2-CT-2004505466.

13. TNO report | MON-RPT-033-DTS-2007-03482 v5.1b December 12, 2007, European Commission 